\title{
LA NATURALEZA JURÍDICA DE LA NEO INTEGRACIÓN REGIONAL: UNASUR
}

\section{A NATUREZA JURÍDICA DA NEOINTEGRAÇÃO REGIONAL: UNASUL}

Pedro Alejandro Duarte LLovera ${ }^{\star}$

Resumen: Nuestro siglo 21, se inaugura con una crisis financiera sin precedentes ocasionada por la explosión de la burbuja de los créditos "subprime" desde los Estados Unidos de Norteamérica. Paralelamente, América del Sur vive un momento especial en lo económico, lo social y lo político. Por el aumento de los precios en la materias primas (conmodities); la participación protagónica y ciudadana, que fortalece y construye un nuevo concepto de democracia, impulsado por la Constitución de la República Bolivariana de Venezuela de 1999, que la diversificó y la proclamó participativa y protagónica. Existe la voluntad política en el continente de gobiernos progresistas (Brasil, Argentina, Venezuela, Uruguay, Bolivia, Ecuador, Perú), que han gestado condiciones para proyectos alternativos, como la neo integración regional (ALBA:2004), (UNASUR:2008) y (CELAC:2009); que van más allá de la visión reduccionista de mercado y del predominio del capital sobre los seres humanos, la explotación intensiva de recursos naturales y la verticalidad en las relaciones. El objetivo es conocer la naturaleza jurídica de la UNASUR, desde su nacimiento como un proceso de integración endógeno y un espacio de diálogo y consenso político en las negociaciones intergubernamentales directas; donde la resolución de controversias constituye el sostén de la seguridad jurídica de los Estados miembros, lo que amerita la construcción de una institucionalidad necesaria, que en su fase fundacional no vislumbra supranacionalidad.

Resumo: Nosso século XXI se inaugura com uma crise financeira causada pelo estouro da bolha de créditos "subprime" nos Estados Unidos da América do Norte. Enquanto isso, a América do Sul vive um momento especial em termos econômicos, sociais e políticos. Em razão do aumento

\footnotetext{
* "Instituto Postal Telegráfico de Venezuela. Ministerio del Poder popular para Ciencia, Tecnología e Innovación de la República Bolivariana de Venezuela"; Facultad de Ciencias Jurídicas y Políticas de la Universidad José Antonio Páez.

Abogado Cum Laude (USM). Especialista en: Derecho Procesal (Salamanca); Derecho Corporativo (UNIMET); Formación Docente (UC). Magíster en: Derecho Procesal (UCAB) y Sociología para el Desarrollo de América Latina (UARCIS). Investigador del MPPPCTI de la República Bolivariana de Venezuela. Catedrático y Conferencista en Resolución Alternativa de Conflictos e Integración Regional.
} 
de preços de matérias-primas (comodities); da participação protagônica e cidadã, que reforça e constrói um novo conceito de democracia, impulsada pela Constituição da República Bolivariana da Venezuela de 1999. Existe vontade política de governos progressistas do continente (Brasil, Argentina, Venezuela, Uruguai, Bolívia, Equador, Peru ) que desenvolveram condições para projetos alternativos, como o da neointegração regional (ALBA: 2004) (Unasul: 2008) e (CELAC: 2009), que vai além da visão reducionista do mercado e do domínio do capital sobre os seres humanos, da exploração intensiva dos recursos naturais e da verticalidade das relações. O objetivo seria determinar a natureza jurídica da UNASUL, desde o seu nascimento como um processo de integração endógeno e como um espaço de diálogo e consenso político nas negociações diretas; no qual a resolução de disputas consubstancia pilar da segurança jurídica dos Estados-Membros e promove a construção de uma institucionalidade necessária, que em sua fase fundacional não vislumbra supranacionalidade.

Palabrasclave: Integración sudamericana, Integración jurídica, Ciudadanía, Identidad, Democracia participativa, Derechos, Obligaciones, UNASUR Palavras-chave: Integração sul americana, Integração jurídica, Cidadania, Identidade, Democracia participativa, Direitos, Obrigações, UNASUL

\section{INTRODUCCIÓN}

En un sentido histórico, la revisión de tradiciones comprende dos narrativas que desde el siglo 19, han reflejado dos modelos de articulación a nivel de los Estado-nación como entidades políticas independientes, así como las relaciones intra e inter hemisféricas:

i.- Por un lado, la idea de una región unida ha sido adoptada como una visión custodiada por los Estados Unidos de Norteamérica nacida en la doctrina Monroe y encarnada en el ideal panamericano de una América libre de la influencia de actores externos en el hemisferio occidental.

ii.- Por otra parte, la visión latinoamericanista que se configura alrededor de los ideales de Simón Bolívar de lograr una unión de las antiguas colonias españolas que comparten una cultura común, lenguaje y un legado histórico hacía la patria grande.

Estas dos visiones dieron sustento a un imaginario regional manifestado en diversas lógicas de cooperación, poder y gestión económica y política. En otras palabras, la práctica del regionalismo ha sido moldeada por un cálculo de "realpolitik" contra el imperialismo externo así como la percepción de herencia común. Estos han sido los conductores de distintos arreglos regionales y proyectos de integración que se han desarrollado tradicionalmente en Sur América, tal como lo 
señala Riggirozzi (2011).

En este orden, como concluye Myrdal (1968), sería banal explicar la integración regional como una consecuencia mística de solidarismo voluntario basado meramente en proximidad cultural, política o económica entre naciones vecinas.

Un balance objetivo de la integración regional latinoamericana, penosamentepareciera ser una tarea aún pendiente, en lenta construcción, fraccionada y marcada por un signo netamente económico o comercial, aspecto que siendo importante no puede seguir siendo el único eje a desarrollar y menos aun para el beneficio de grupos reducidos de corporaciones y transnacionales, aprovechando plenamente las ventajas de la globalización financiera.

La sociedad actual es cada vez más globalizada, el sistema capitalista se ha servido de la economía política como mecanismo para enajenar la idea que en el comercio mundial todos pueden ganar, primero dentro de sus fronteras y luego mas allá de ellas, pues la integración económica desde el siglo 20, se ha considerado y se ha justificado, como un medio para avanzar hacia la formación de una comunidad latinoamericana, que se suponía iba a mejorar sus condiciones sociales, garantizando ciertos ingresos en sus capas sociales.

El Consenso de Washington demarcó en los años 90, en América Latina modelos de desarrollo que conllevaron a instrumentar políticas cuyos ejes centrales fueron la plena libertad de mercado, la disciplina fiscal y la desregulación del Estado, privatizando las empresas públicas, achicando el campo de acción del Estado para entregárselo a los intereses privados y de las transnacionales; destacando que tal Consenso no es más que un acuerdo de políticas de estabilización y ajuste que involucra a las instituciones financieras mundiales, tales como: el Banco Mundial, Fondo Monetario Internacional (FMI), Banca Internacional, Gobiernos y Autoridades del ámbito financiero. La integración en la región se dio por bloques económicos en marco de guerras económicas de los países industrializados, en donde la nación subdesarrollada sigue siendo parte del territorio a ocupar, en este nuevo reparto por las vías del mercado.

De tal manera, que la integración en el continente, ha tenido un carácter predominantemente subregional, privilegiando la construcción de procesos de integración parciales, los cuales no han abarcado la totalidad de los países que comparten su espacio, sea por factores geográficos, económicos, políticos y culturales, que han impedido la integración plena de todos los Estados Suramericanos dentro de un solo proceso de integración.

Tratando de revertir esta situación, tal como lo señala Salgado (2010), se celebró la I Cumbre de Presidentes Sudamericanos en Brasilia, siendo la primera vez que los gobernantes de los doce países se reunían para tratar asuntos de interés común, donde el punto más importante 
fue el cambio de enfoque integracionista en el plazo más corto posible, mediante la concertación en temas claves como: infraestructura, transporte, energía y telecomunicaciones.

Posteriormente, la II Cumbre de Presidentes Sudamericanos, celebrada en Guayaquil en el año 2002, impulsó y refirmó la ya conformada iniciativa para la Integración de la Infraestructura Regional Suramericana-IIRSA, con la finalidad de lograr un espacio integrado físicamente por medio de carreteras, puertos, aereopuertos, telecomunicaciones, infraestructura energética, entre otros, con el objetivo de lograr que la producción de nuestros países tengan oportunidad de ser comercializadas dentro y fuera del sub continente, constituyendo el intercambio comercial a través de la infraestructura como un instrumento para lograr el desarrollo económico y social.

La III Cumbre de Presidentes Sudamericanos, celebrada en Cuzco en el año 2004, buscó dar un salto sustancial en la relación entre los países, por ello se planteó la necesidad de conformar una Comunidad Sudamericana, como instrumento para lograr un espacio regional integrado. La Declaración del Cuzco, alumbró el nacimiento de la Comunidad Sudamericana de Naciones (CSN), como un espacio de concertación política tendiente a fortalecer la integración regional mediante acciones concretas.

Es necesario decir, que los Presidentes accedieron a establecer un programa de acción que avanzaría paulativamente dentro del marco de la CSN, aclarando que no buscaban crear una nueva institucionalidad, por lo cual no firmaron ningún acuerdo o tratado, que diera paso a un nuevo ente de integración.

La IV Cumbre de Presidentes Sudamericanas y la Primera Cumbre de la Comunidad Sudamericana de Naciones celebrada en Brasilia en el año 2005, tuvo como objetivo central el avanzar en acciones concretas, tendientes a consolidar el proceso de integración sudamericana, a pesar de los avances obtenidos se ponderó la necesidad de dar mayor profundidad a los contenidos de la integración y a las formas institucionales de que debería revestirse.

En la V Cumbre de Presidentes Sudamericanos y la II Cumbre de la Comunidad Sudamericana de Naciones, celebrada en Cochabamba en 2006, se definen los principios y objetivos del nuevo modelo de integración, aprovechando las experiencias positivas de los mecanismos de integración Subregional existentes, como el CARICOM, la CAN y el MERCOSUR, lo cual se hace en los siguientes términos: solidaridad y cooperación en la búsqueda de una mayor equidad, reducción de la pobreza y las asimetrías, soberanía, respeto a la integridad territorial y autoderminación de los pueblos, resolución pacífica de controversias, democracia y pluralismo, respeto a los derechos humanos, desarrollo sostenible, entre otros. 
Es en la Declaración de Margarita-Venezuela, el 16 de abril de 2007, que los Presidentes y Jefes de Estado Sudamericanos decidieron acelerar el proceso de integración iniciado con la CSN en 2004, adoptando el nombre de Unión de Naciones Suramericanas, dejando de ser un foro de encuentro entre los países para convertirse en un proceso de integración con institucionalidad y funcionarios responsables para cumplir los objetivos planteados.

Es entonces; gracias al surgimiento de nuevos motores y líderes progresistas de izquierda, tanto como la renovación del contrato social en buena parte de los países de América Latina, que se abre un espacio diferente para consolidar alternativas de políticas sociales y de desarrollo tanto nacionales como regionales.

A diferencia de crisis mundiales anteriores, la región se encuentra posicionada de manera más firme para enfrentar política y económicamente cuestiones claves de identidad, autonomía y cooperación, tal cual lo señala, Iglesias (2008). Por el aumento de los precios en la materias primas (conmodities) que se vende a otros países de mayor grado de desarrollo, aunque persistiendo la inadecuada distribución del ingreso que aún genera pobreza y desigualdad, como consecuencia de la injusta estructura de la relación comercial inter industrial de los que venden materia prima, y luego compran e importan como productos manufacturados. Aunado al resurgimiento de clases medias, el activismo ciudadano que fortalece el concepto de una democracia participativa y protagónica.

En tal sentido, a pesar del indisputable énfasis comercial que impulsan los proyectos de integración regional, un nuevo escenario de política económica en América Latina abre un espacio para la emergencia de nuevas articulaciones políticas y sociales que reclaman, y tal vez re-inventan, principios de solidaridad, complementariedad, cooperación y colectivismo regional.

De esta manera, existe la coincidencia de la crisis del neoliberalismo con una creciente difusión del poder financiero e ideológico de la mano de nuevos actores globalizantes en Asia, nuevos poderes regionales (Brasil, Argentina, Venezuela, Uruguay, Bolivia, Ecuador, Perú) y un inequívoco decrecimiento de la influencia y el poder de los EEUU como líder regional. Ante este panorama, tenemos entonces, la fundación de un regionalismo alternativo; que plantea las relaciones sur con sur, no solo por intereses económicos sino también en los aspectos sociales, culturales, políticos, energéticos y ambientales entre otros, para reforzar los lazos de cooperación técnica horizontal del sur con sur, para conocer y fortalecer buenas prácticas de cada país en materia de políticas nacionales aplicadas al interior de cada país. Esta propuesta incorpora la recuperación de la autonomía de los países frente a la globalización, lo que implica la capacidad decisoria de los Estados miembros para 
elegir el camino más adecuado para las estrategias de desarrollo, tanto a nivel nacional como regional, pero respetando la autodeterminación y diversidad de los pueblos que lo compone.

Ahora bien, se identificaron las primeras necesidades y dificultades de una estructura internacional que estaba construida para mantener las relaciones neo coloniales, donde tanto los mecanismos tradicionales de resolución de conflictos, como los organismos internacionales de gestión colectiva, es decir, los órganos supranacionales, estaban pensados para entregar la mayoría del control a los países del norte. Tal sería el caso del Centro Internacional de Arreglos de Disputas Relativas a Inversiones (CIADI), el cual es un foro de arbitraje establecido en 1966 para facilitar el arreglo de disputas entre gobiernos e inversionistas extranjeros, dependiente del Banco Mundial, constituyéndose en organismo que por su lógica interna, por su secretismo en un instrumento de control de nuestros países en manos del Imperio. Basta con revisar las estadísticas de los laudos arbitrales emitidos, para darse cuenta que el mayor porcentaje de las demandas incoadas van en contra de los Estados miembros de la UNASUR y a favor de las transnacionales.

En este sentido, debemos avanzar desde la UNASUR a la construcción de un centro de arbitraje suramericano para la resolución de los conflictos de inversiones, pues al lado de las normas supranacionales y las intergubernamentale $4 \mathrm{~s}$, tenemos otras normas de interés para la integración, y son precisamente las de inversiones, que requieren de mecanismos neutrales e imparciales para su efectiva resolución.

\section{ARBITRAJES EN EL CIADI POR REGIÓN FUENTE CIADI (2012)}

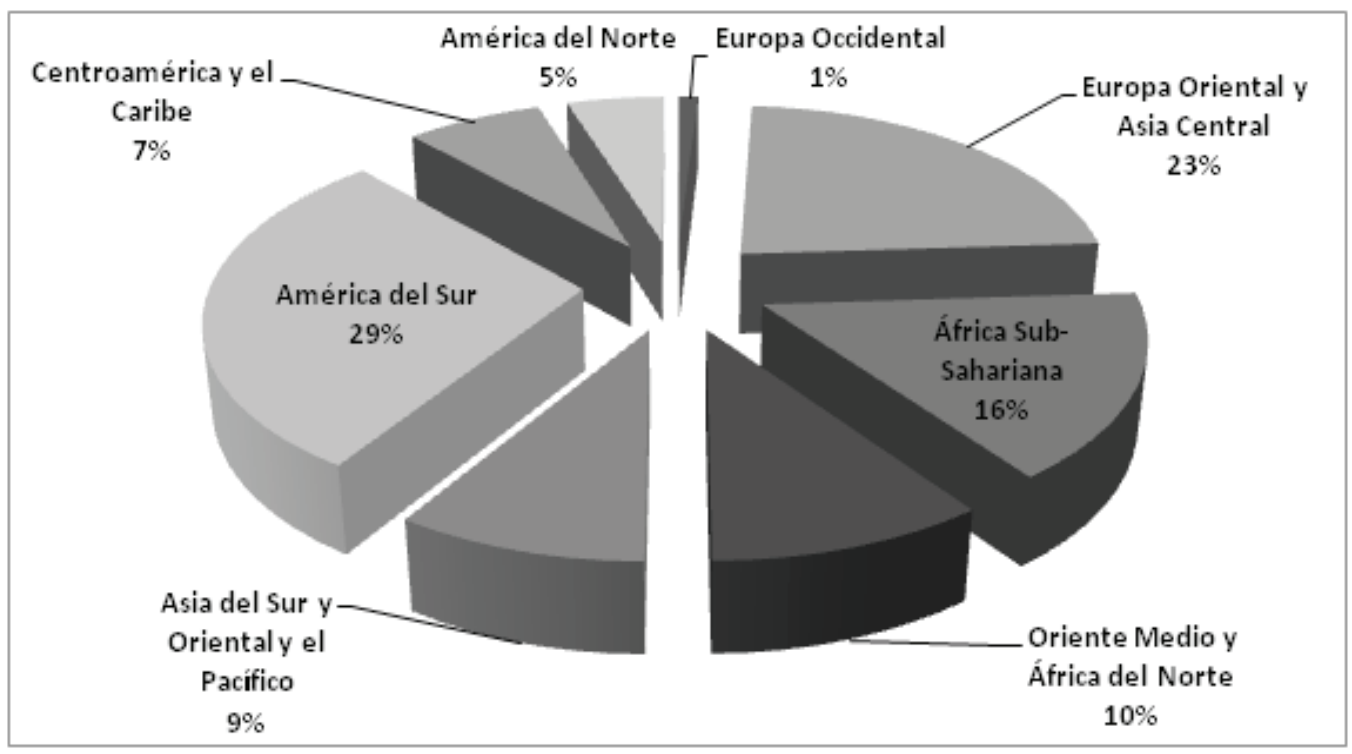


NACIONALIDAD DE LOS ÁRBITROS QUE DICTAN LOS LAUDOS ARBITRALES DEL CIADI

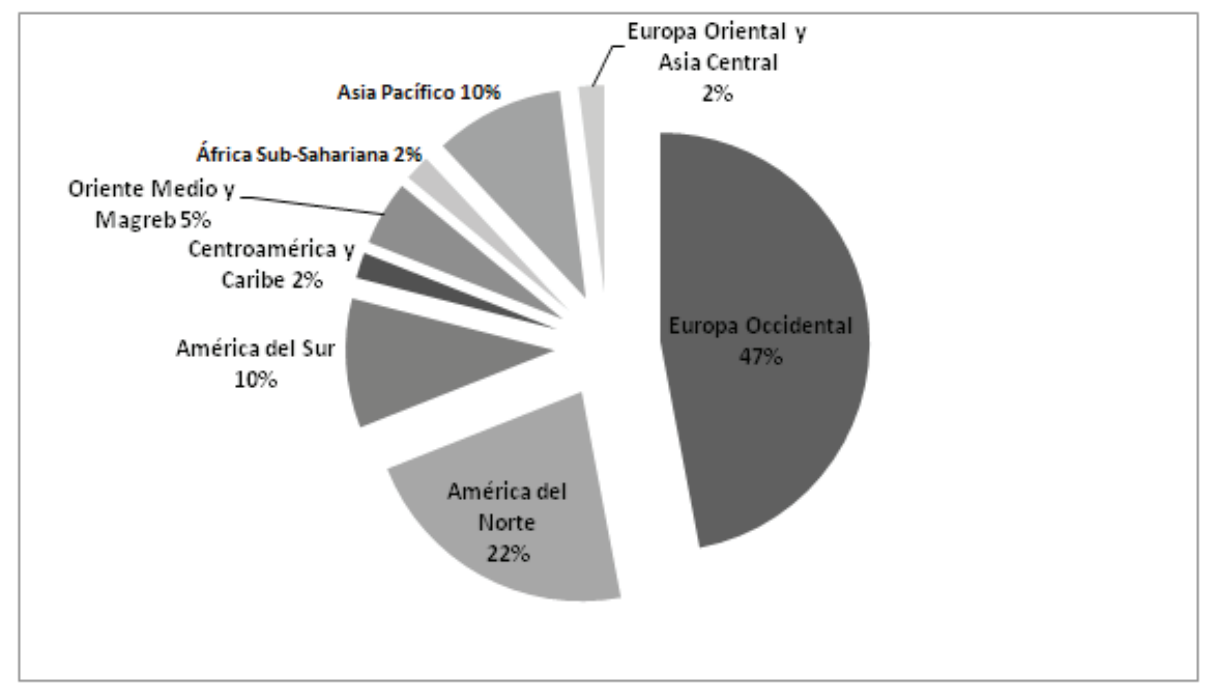

Igualmente, es conveniente resaltar el impulso y apoyo que desde el gobierno de la República Bolivariana de Venezuela, liderizado por el Comandante y Presidente Eterno "Hugo Chávez Frias" se ha ido gestando para ir coloreando el escenario propicio para que los países del continente participaran en la comprensión de una democrática participativa y protagónica, coadyuvando a fortalecer conceptos de soberanía nacional en Bolivia, Ecuador, Argentina y Brasil ante los continuos ataques y presiones imperiales, pues desde la lógica de la cooperación y la complementariedad, brindar ayudas a cada uno de estos países más que hacerlo individualmente, es fortalecer la Nueva Integración Regional Alternativa y la seguridad democrática.

Ahora bien, a los fines de describir una dimensión jurídica de la llamada Neo-Integración Regional Alternativa que representa la UNASUR, debemos tomar como punto de partida la fecha cierta de su nacimiento, y para ello debemos comenzar por el primer artículo de su Tratado Constitutivo, que establece claramente la voluntad de existir, el cual fue consensuado sin dificultad, destacando que por primera vez en la historia de nuestro continente se reúnen condiciones excepcionales: tanto objetivas como subjetivas, que permitieron que doce autoridades políticas apostarán a este nuevo modelo de integración regional, con lo que se reafirma la clara intención de avanzar conforme se expreso en la Cumbre de Jefes y Jefas de Estado y de Gobierno en Brasilia-República Federativa del Brasil, el 23 de mayo de 2008, con la aprobación del Tratado Constitutivo de la UNASUR, y como consecuencia inmediata se convierte en una organización dotada de personalidad jurídica internacional, que no es otro cosa que tener la capacidad para ser titular de derechos y obligaciones. 
En tal sentido, un proceso de integración de tal magnitud requiere como condición sine qua non la correspondiente y correcta ordenación jurídica, tendiente al establecimiento de deberes de obligatorio cumplimiento y derechos que de igual forma deben garantizarse a todos los países miembros; siendo indispensable la instauración de normas adjetivas y procesales, que permitan el desarrollo de procedimientos inmaculados, eficaces y efectivos que garanticen el cumplimento de los deberes y derechos que se generan con los Tratados de Integración. $\mathrm{Y}$ desde este momento, se debe hablar del desarrollo de una institucionalidad necesaria, que permitió avanzar en la consolidación de su etapa fundacional; pues los doce países que la integran ratificaron y consolidaron un nuevo modelo de integración con identidad propia, en medio de la diversidad y las diferencias, es decir, el logro más significativo es convivir en la diversidad ideológica y política, aceptando enfoques políticos diversos, construyendo así un espacio de diálogo y libre consenso político indispensable para seguir avanzando; siendo está su intención política.

Siguiendo la obra maestra "El ABC del Derecho para la Integración" del Dr. Oswaldo Salgado Espinoza” (2010), debemos recordar que los procesos de integración tradicional tienen dos formas bien definidas de práctica o modo de ejecutar los objetivos que persiguen y son conferidos a sus Órganos Facilitadores, que son:

i.- Con mecanismos Autónomos, Supranacionales o Comunitarios, que se denomina Derecho Comunitario o Supranacional; y.

ii.- Con mecanismos Intergubernamentales, denominado Derecho Intergubernamental.

Sin embargo, dados los avances modernos y la necesidad de contar con modelos de gestión eficientes, la tendencia del Siglo 21I y de los Procesos de la Neo-Integración, debe ser de contar con sistemas mixtos, con tendencia dominante de una de ellas, porque ambos mecanismos son válidos en función de los diversos objetivos que persigue la integración.

Considerando que en los procesos de integración intergubernamental, hay aspectos que se pueden ejecutar con mayor eficiencia sin necesidad de conseguir los consensos (intergubernamentalidad), para cosas o aspectos elementales y de simple gestión; y contrariamente, en los casos de integración comunitaria o supranacional, hay aspectos que no deben realizarse de forma autónoma por los órganos facilitadores creados por los procesos de integración, dado que son temas de mucha sensibilidad y se requiere el consenso.

Teniendo en cuenta estos aspectos y la normativa existente, la UNASUR posee un Sistema de Integración Intergubernamental con una incipiente y casi nula acción de espacios comunitarios o supranacionales, por ello deben existir mayores expresiones de acción autónoma, para ciertos órganos facilitadores, que le permitan mayor agilidad y 
optimización de los recursos para cumplir los objetivos planteados de manera efectiva, eficiente y eficaz.

En este contexto, a los órganos facilitadores se les confía ya no la conservación del status quo vigente como tal, sino la eficiencia de los objetivos de la integración, por ello, se necesita la progresiva adecuación de su ser efectivo a su deber ser normativo o reglamentario.

La UNASUR requiere un nuevo paradigma o modelo de gestión, que permita a sus Órganos Facilitadores realizar y ejecutar acciones autónomas de simple gestión o domésticas.

En consecuencia, las grandes metas y objetivos (lo que en un sistema de planificación estratégica se denomina la visión) sea el punto de llegada de las acciones que se persigan en un modelo de gestión. De esta gran visión debe derivarse una estrategia que permita en el largo plazo conseguir y mantenerla (de ser posible) con una actitud de mejoramiento continuo.

Independientemente, tenemos un proceso de integración suramericano en base al consenso, pues ninguna decisión se puede tomar en contra de un Estado Miembro. De esta forma todos los Estados están seguros que serán tomados en cuenta a la hora de decidir. Este es el segmento que une a todos los integrantes de la UNASUR, es decir, en una primera etapa no se apuesta a una integración dura, no se apuesta a supranacionalidad alguna, para no repetir modelos de integración; donde no exista ningún tipo de ventaja a la hora de tomar decisiones a favor de los más poderosos; hasta ahora no vislumbra la creación de ningún órgano jurisdiccional, ya que ello implicaría cierto grado de supranacionalidad. En consecuencia, sería incompatible con su naturaleza y principios rectores, al menos en esta etapa de creación.

Se podrá argumentar que el consenso puede bloquear la toma de decisiones si un gobierno decide oponerse a los acuerdos de la mayoría. Esto es posible, pero al mismo tiempo es la garantía que tienen todos los Estados Suramericanos de incidir en el proceso de formación de una integración, que nace adaptándose a nuestra identidad y más profundamente acorde a nuestras realidades y necesidades reales económicas, políticas, sociales, culturales, jurídicas y educacionales.

La UNASUR, apuesta a una integración alternativa en base al diálogo y consenso político de los Estados miembros, por lo cual contempla un mecanismo de resolución de controversias basado en las negociaciones directas e intergubernamentales, que le garanticen a todos los Estados miembros la igualdad en voz y voto. Estos mecanismo de resolución de controversias se refiere básicamente a la interpretación y aplicación de las normas del Tratado Constitutivo, aplicable a una etapa fundacional, embrionaria y de construcción; y es precisamente por ello que no se plantea un mecanismo de índole jurisdiccional, ya que esto lleva consigo implícita un grado de supranacionalidad, 
que por los momentos atendiendo a su espíritu no es su prioridad. Insisto su prioridad es la creación de un espacio de consenso y diálogo político que en la diversidad y a través de negociaciones directas intergubernamentales den solución a las controversias que existían, las que existen y puedan surgir en el futuro, todo ello con el fin último de construir una nueva geopolítica en nuestro continente.

Cabe destacar, que en América del Sur si es posible establecer nuestros propios mecanismos de resolución de controversias, pues contamos con capacidades humanas, técnicas, fortalezas y juristas para hacerlo.

La UNASUR es un proceso de integración innovador más amplio que abarca todas las áreas donde los Estados puedan llegar asumir acuerdos concretos a nivel de la energía, la adecuada explotación de los recursos naturales, la infraestructura, las finanzas, las políticas sociales, la educación, entre otros, abrazando a su vez lo político, lo social, ambiental, cultural y económico

En este escenario la normatividad son los instrumentos que facilitan o entorpecen el éxito de los logros, por ello, debemos apostar por una coherente reglamentación que en verdad facilite la gestión y no la dificulte. Y debemos, ante todo, unirnos "Unión que-decía nuestro Libertador en su Carta de Jamaica- no nos vendrá por prodigios divinos sino por efectos sensibles y esfuerzos bien dirigidos" hacia la consolidación de la Patria Grande.

De tal manera que la esencia y naturaleza jurídica de la UNASUR pudiera puntualizarse en los siguientes términos:

1.- Por su consentimiento, es una forma de integración voluntaria existiendo horizontalidad en sus relaciones, sin la existencia de un Estado hegemónico que imponga su criterio a los demás.

2.- Por su cumplimiento y resultados ha sido eficaz, eficiente y efectivo; haciendo visible la ruptura del hilo constitucional en Paraguay y Honduras y lograr neutralizar los intentos del golpe de Estado en Ecuador, Bolivia y Venezuela.

3.- Por su duración se aspira una permanencia en la adecuada planificación y empoderamiento de sus miembros para cumplir sus objetivos y lograr sus fines, plasmando una institucionalidad sólida.

4.- Por su ámbito es integral, porque abarca todos los campos de la actividad humana: económico, social, cultural, jurídico y político.

5.- Por su nivel de responsabilidad se proyecta sustentable por ser económicamente rentable, socialmente justo y respetuoso de la pacha mama y el buen vivir.

6.- Por su interés es empoderado pues debe tener una gran participación, consenso, motivación y sentido de pertenencia de los pueblos y gobiernos, pues en definitiva la integración debe ser para beneficiar a las personas. 
7.- Por su incidencia es influyente en el contexto mundial, ya que contribuye al desarrollo de una nueva geopolítica internacional en la cual tome cuerpo un mundo multicéntrico y pluripolar que permita lograr el equilibrio del universo y garantizar la paz planetaria. (Chávez: 2012).

8.- Por el nivel transformador es revolucionario ya que se mantiene una horizontalidad en las relaciones entre países, caracterizados por ser anti-hegemónicos, humanistas, solidarios y complementarios.

9.- Por el grado de cambios es un proceso de neo-integración puesto que toma como base los elementos endógenos, culturales, sociales, económicos y políticos, considerando sus debilidades, potencialidades y sabidurías de los pueblos que lo integran.

10.- La UNASUR construye cultura para la Paz, puesto que promociona la resolución alternativa de las controversias a través de Centros de Mediación y Arbitraje en materia de otras normas de interés para la integración, como lo es el tema de las inversiones, lo que a su vez permite coadyuvar en la formación de mediadores y árbitros con identidad latinoamericana.

11.- La UNASUR es una organización con personalidad jurídica internacional y su Tratado Constitutivo es del tipo:

i.- Multilateral, por involucrar a más de dos Estados;

ii.- Abierto, ya que de conformidad al artículo 20 de su Tratado Constitutivo: "A partir del quinto año de la entrada en vigor del presente Tratado y teniendo en cuenta el propósito de fortalecer la unidad de América Latina y el Caribe, el Consejo de Jefas y Jefes de Estado y de Gobierno podrá examinar solicitudes de adhesión como Estados Miembros por parte de Estados Asociados que tengan este status por cuatro (4) años, mediante recomendación por consenso del Consejo de Ministras y Ministros de relaciones exteriores. Los respectivos protocolos de adhesión entrarán en vigor a los treinta (30) días de la fecha en que se complete su proceso de ratificación por todos los Estados Miembros y el Estado adherente..." De tal manera, la tipología abierta se sub-divide de manera específica en que a su vez está restringido a los Estados de América Latina y del Caribe, ya que sólo estos podrán ser Estados asociados en virtud de que conforme al artículo 19 del Tratado Constitutivo de la UNASUR: “...Los demás Estados de América Latina y el Caribe que soliciten su participación como Estados Asociados de UNASUR, podrán ser admitidos con la aprobación del Consejo de Jefes y Jefas de Estado y de Gobierno...”;

iii.- Contrato, por cuanto establece derechos y obligaciones recíprocamente condicionados entre sus Estados miembros; y

iv.- Normativo, ya que contiene un conjunto de disposiciones de alcance general y abstracto aplicables por igual a los miembros de la organización dotada de personalidad jurídica internacional. 
Finalmente, siguiendo la Decisión sobre los Lineamientos para un Plan de Acción de la Unión de Naciones Suramericanas (UNASUR), adoptada por los Jefes y Jefas de Estado y de Gobierno el 23 de mayo de 2008 en Brasilia, República Federativa del Brasil; además del Informe de la VIII Reunión del Grupo de Trabajo Mecanismos de solución de controversias en materia de inversiones en el marco de UNASUR, Montevideo 19 y 20 de mayo de 2009, se presenta una primera propuesta para contribuir al desarrollo de su institucionalidad: Es la construcción de un Centro de Asesoría Legal Permanente para UNASUR, que por lo demás se encuentra en una fase de creación, por lo cual no existe nada escrito al respecto más que las normas del Tratado Constitutivo, los informes descritos; y las experiencias de otros Centro de Asesorías Legales.

En esta sintonía, existe un proyecto de Decisión para el Establecimiento del Centro de Asesoría Legal en Materia de Inversiones de UNASUR, el cual tendrá un carácter de libre adhesión por parte de los países miembros de la UNASUR de conformidad con lo previsto en el articulo 13 el Tratado constitutivo de la UNASUR; quedando facultado el país miembro que así lo desee, eximido tanto de participar del Centro como de realizar contribuciones o aportes de cualquier tipo al mismo. No existen imposiciones obligatorias de tipo supranacional, pues precisamente lo que se busca es que ningún Estado tenga mayor injerencia que otro por ninguna circunstancia.

El Centro tiene por objeto proporcionar formación, apoyo y asesoría jurídica a los Estados Miembros para la prevención y solución de controversias en materia de inversiones; destacando que este Centro no es una instancia jurisdiccional.

El Centro deberá, a solicitud de los Estados Partes, cuando corresponda:

1. Proporcionar asesoría jurídica en asuntos relativos aderecho internacional en materia deinversiones, incluyendo la prevención y solución de controversias;

2. Proveer asistencia técnica yjurídica, incluyendola representación legal en los asuntos relacionados con procedimientos de solución de diferencias en materia de inversiones en que este involucrado alguno de los Estados Partes ante cualquier foro internacional;

3. Brindar capacitación a funcionarios gubernamentales para la prevención, preparación y coordinación en la solución de controversias relativas a inversiones;

4. Proporcionar asesoría jurídica y técnica a los Estados Partes en la negociación e implementación de acuerdos internacionales que contengan disposiciones en materia de inversiones;

5. Promover el intercambio de experiencias, información y cooperación técnica entre los Estados Partes para la prevención y 
solución de controversias enmateria de inversiones.

6. Desempeñar cualquier otra función que le encomiende la Asamblea General.

Cabe destacar, que las seis funciones anteriormente descritas se implementarán de manera simultánea y con carácter gradual, de acuerdo al Plan de Trabajo anual del Centro, sujeto a su capacidad técnica y disponibilidad presupuestaria.

Tenemos una necesidad inminente: nuestros países son vulnerables a las controversias de inversionista (transnacional) versus Estado, además del alto costo, por la falta de formación en la defensa de nuestros Estados miembros.

La importancia está en examinar a la brevedad posible iniciativas, incluyendo aquellas de carácter multilateral, dirigidas a la creación de un centro de asesoría jurídica para controversias inversionista -Estado, que sea independiente y de alta capacidad técnica, con el fin de brindar apoyo técnico para prevenir y atender este tipo de controversias.

En otras palabras, formación, asistencia técnica y prevención de controversias; para poder equipar a los países miembros de la UNASUR con las herramientas necesarias para manejar controversias y para darles capacidad de litigio internacional. Es muy importante dejar claro, que no estamos en presencia de un órgano jurisdiccional, es simplemente un centro que sirva para prestar asesoría jurídica a los Estados Miembros.

Igualmente, asesoría y representación en controversias de inversión, prestando servicios de apoyo ad-hoc para Estados que necesitan asesoría jurídica y representación, tal como lo necesito en su oportunidad PDVSA (Venezuela), para poder enfrentar la demanda leonina de la Exxon Mobil, donde tuvo que contratar los servicios de asesoría jurídica internacional, lo cual significó grandes costos para el país. La idea es contar con un Centro de asesoría permanente para nuestros países, que además contribuyan con el adecuado desarrollo de su institucionalidad, específicamente la construcción de mecanismos efectivos de resolución de diferencias.

\section{REFERENCIAS BIBLIOGRÁFICAS}

DUARTE P. (2012). La dimensión jurídica de la Unión de Naciones Suramericanas.

VI Congreso ALACIP de Ciencia Política 2012. Quito: FLACSO.

IGLESIAS E. (2008) "América Latina: Integración Comercial, Complementariedad Productiva y Cooperación". En ALTAMANN, J. y ROJAS A. F. (comps.) América Latina y el Caribe: ¿fragmentación o convergencia? Experiencias Recientes de la Integración. Quito:FLACSO y Ministerio de la Cultura.

MYRDAL G (1968). Asian drama: an enquiry into the poverty of regions. New York. Pantheon. 
MONEDERO J. Entrevista abierta, realizada el 23 de octubre de 2012 en la Universidad Complutense: de Madrid.

SALGADO O. (2012) Entrevista abierta realizada el 14 de junio de 2012 en la sede de la Secretaría General Permanente de la UNASUR. Quito.

SALGADO O. (2010). Colección Sendero Suramericano del Sigo 21. Tomo 1: El ABC del Derecho para la Integración.Quito: EDISLAT.

RIGGIROZZI P. (2011). Hacia un regionalismo post-neoliberal en América Latina: Reforma o Ruptura. Brasil. EdUECE. 